Endocrinol. Japon. 1966, 13 (1), 75 78

\title{
NOTE
}

\section{CHROMĄTOGRAPHIG SEPARATION OF VARIOUS 17-HYDROXYCORTICOSTEROIDS AND 17-KETOSTEROIDS}

\author{
ToKuICHIRo SEKI \\ Department of Genetics, Osaka University Medical School, Osaka
}

\section{KeISH MATSUMOTO}

\section{Department of Pathology, Osaka University Medical School, Osaka}

The chromatographic separation of 17-hydroxycorticosteroids has been performed by paper and column partition chromatography, and both methods have been very useful for the quantitative separation of steroids in biological fluids (Gold and Crigler, 1963; Starnes et al., 1963; Jhonson et al., 1959).

On the other hand, it has been found that sugars (Samuelson and Swenson, 1963) and some organic acids (Seki, 1966) could be separated by partition chromatography on ion exchange resins. In these systems, the ion exchange resin phase rich in polar solvent served as the stationary phase and a less polar liquid phase served as the moving phase. This method has now been applied in the separation of various 17-hydroxycorticosteroids and 17-ketosteroids and satisfactory results have been obtained using liquid phases with the lower polarity, i.e., a mixture of ethanol, benzene, $n$-hexane and water $(20: 100: 40: 1$ by vol., eluent A) and a mixture of ethanol, benzene, $n$-hexane and water $(90: 30: 360: 2$ by vol., eluent $\mathrm{B})$.

\section{MATERIALS AND METHODS}

Ion exchange resin

Dowex 50W-X4 (200-400 mesh) in the sodium ion form was classified hydraulically according to the method of Hamilton (1958), as modified by Vassiliou and Kunin (1963), and particles of $63 \pm 3 \mu$ were obtained. These were transferred to a glass filter and washed successively with $6 \mathrm{~N}$ hydrochloric acid (10 vols.), water, $2 \mathrm{~N}$ sodium hydroxide (10 vols.), water, $2 \mathrm{~N}$ hydrochloric acid (10 vols.), water and finally 95 per cent ethanol (10 vols.).

\section{Preparation of the column}

a) For eluent $A$. The washed resin was equilibrated on a glass filter with a mixture of benzene, ethanol and water (100:50:1 by vol.), and then suspended by swirling in about 2 volumes of the same solvent. The suspension was poured into a chromatographic tube through a small funnel fitted with a ground joint and allowed to settle. The next day, the solvent above the column was removed and the column was washed with eluent A. When about $300 \mathrm{ml}$ of the solvent had been passed through the column, it was ready for use.

Received for publication October 5, 1965. 
b) For eluent B. The washed resin was first washed with a mixture of ethanol, benzene and water (100:50:1 by vol.) then with eluent B (30 vols.). Then the resin was suspended in two volumes of eluent B and packed into a column, as described above for eluent A. After about $200 \mathrm{~m} l$ of the solvent had been passed through the column, it was ready for use.

\section{Chromatographic separation of synthetic mixtures}

A solution $(0.7 \mathrm{ml})$ of steroids, in a solvent mixture of slightly higher $n$-hexane content than that used for packing the column, was added to the column and elution was performed with the solvent used for packing the column. The effluent was collected in fractions of 20 drops in test tubes $(15 \times 105 \mathrm{~mm})$ using a drop count type automatic fraction collector. The solvent was allowed to evaporate at room temperature and the steroids remaining in the test tubes were estimated by the Porter-Silber reaction (Silber and Porter, 1957) or by the Nathanson-Wilson modification of the Holtorff-Koch method (Engel, 1954).

\section{RESULTS AND DISCUSSION}

As shown in Figures 1 and 2, steroids which were difficult of impossible to separate from each other by elution chromatography on partially esterified Amberlite IRC-50 (Seki and Matsumoto, 1963; Okano et al., 1963) could be separated efficiently by partition chromatography on Dowex 50W-X4. With eluent A, the elution sequence was quite similar to that of normal phase partition chromatography. Allotetrahydrocortisol overlapped tetrahydrocortisol, although these steroids

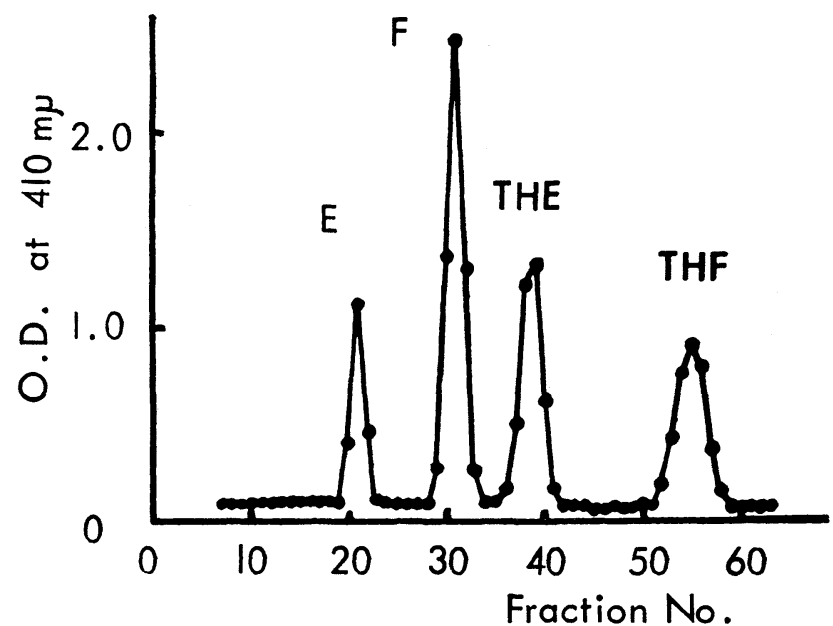

Fig. 1. Elution of 17-hydroxycorticosteroids

The compounds in the order of their elution from the column are: cortisone

(E), cortisol (F), tetrahydrocortisone (THE) and tetrahydrocortisol (THF)
Column size : $0.5 \times 75 \mathrm{~cm}$
Flow rate: 4 fractions per hr.

Moving phase: eluent $A$

Temperature : $21^{\circ} \mathrm{C}$

Fraction size : 20 drops 


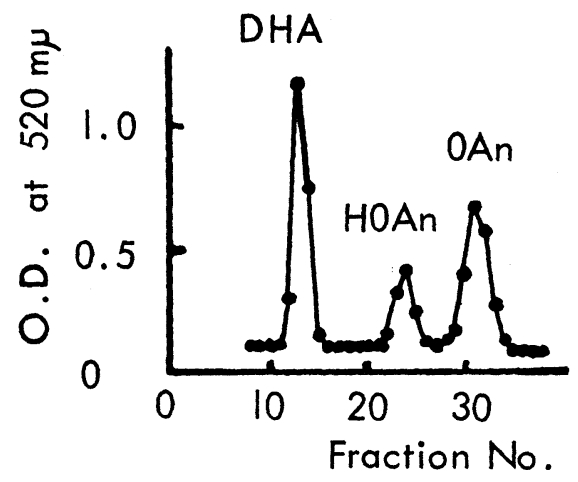

Fig. 2. Elution of various 17-ketosteroids

The compounds in the order of their elution from the column, are: dehydroepiandrosterone (DHA), $11 \beta$-hydroxyandrosterone (HOAn) and 11 -ketoandrosterone (OAn).

Column size: $0.5 \times 64 \mathrm{~cm}$

Flow rate: 3 fractions per $\mathrm{hr}$.

Moving phase: elvent $B$

Temperature: $21^{\circ} \mathrm{C}$

Fraction size: 20 drops per fraction

could be separated with the aqueous eluent (Okano et al., 1963). With eluent B, $11 \beta$-hydroxyandrosterone was eluted earlier than 11-ketoandrosterone. This may be due to the higher ethanol : benzene ratio of eluent $B$ than of eluent $A$. When an eluent of higher benzene content and lower ethanol content was used, e.g. a mixture of ethanol, benzene, $n$-hexane and water $(10: 160: 160: 0.2$ by vol.), 11ketoandrosterone was eluted faster than $11 \beta$-hydroxyandrosterone, although in this case the peak width became much broader. There was about 80 to 90 per cent recovery of steroids from the chromatographic column except for $11 \beta$-hydroxyandrosterone (recovery, 55\%) and the column could be used repeatedly. The chromatographic system described above was satisfactory for the separation of 17-hydroxycoricosteroids and 17-ketosteroids present in the urine of new born infants.

\section{ACKNOWLEDGEMENTS}

The authors express their gratitude to the Shionogi \& Co. for generous financial support of this investigation; to Dr. T. F. Gallagher, who kindly provided samples of tetrahydrocortisol and tetrahydrocortisone; and to Dr. J. Endo, who kindly provided samples of $11 \beta$-hydroxyandrosterone and 11-ketoandrosterone,

\section{REFERENCES}

Engel, L.L. (1954). in Methods of Biochemical Analysis. Ed. by D. Glick, Vol. 1, Interscience Publishers, New York, p. 479.

Gold, N.L. and J.F. Grigler (1963). J. Clin. Endocrinol. and Metabolism 23, 156.

Hamilton, P.B. (1958). Anal. Chem. 30, 914. 
Johnson, D.F., E. Heftmann and A.L. Hayden (1959). Acta Endocrinol. 23, 341.

Okano, K., K. Matsumoto, A. Akehi, S. Mizutani. H. Kikkawa and T. Seki (1963). Endocrinol. Japon. 10, 221.

Samuelson, O. and B. Swenson (1963). Anal. Chim. Acta 28, 426.

Seki, T. (1966). J. Chromatog. in press.

Seki, T. and K. Matsumoto (1963). J. Chromatog. 10, 400.

Silber, R.H. and C.C. Porter (1957). in Methods of Biochemical Analysis. Ed. by D. Glick, Vol. 4, Interscience Publishers, New York, p. 139.

Starnes, W.R., T.F. Partlow, M.C. Grammer, L. Kornel and S.R. Hill, Jr. (1963). Anal. Biochem., 6, 82.

Vassiliou, B. and R. Kunin (1963). Anal. Chem. 35, 1328. 